\title{
1 Gut cancer increases the risk for Drosophila to be preyed upon by hunting spiders
}

2 David Duneau ${ }^{1,2 *}$ and Nicolas Buchon ${ }^{3}$

3

$4{ }^{1}$ Université Toulouse 3 Paul Sabatier, CNRS, IRD; UMR5174 EDB (Laboratoire Évolution \& 5 Diversité Biologique); Toulouse, France.

$6 \quad$ Instituto Gulbenkian de Ciência, Rua da Quinta Grande 6, P-2780, Oeiras, Portugal

$7 \quad{ }^{3}$ Cornell Institute for Host Microbe Interactions and Disease, Department of Entomology, Cornell

8 University, Ithaca, NY 14853, USA.

9

10 * Corresponding author: David Duneau.david.duneau @ gmail.com

11 Keywords: Drosophila, cancer, infection, bacteria, spider, predation

13 Acknowledgements. We thank Violette Chiara, Jean-Baptiste Ferdy, Raphaël Jeanson, and Daniel

14 Zurek for thoughtful discussion; Pierrick Blanchard, Dieter Ebert, Simon Fellous, Sabine Noebel, and

15 Jennifer Regan for their comments on the manuscript; Cole Gilbert for providing the jumping spiders

16 used in the cancer trials; and Christian Faucher for laboratory support. DD was supported by the

17 French Laboratory of Excellence project 'TULIP' (ANR-10-LABX-41; ANR-11-IDEX-0002-02) and

18 the LIA BEEG-B (Laboratoire International Associé-Bioinformatics, Ecology, Evolution, Genomics

19 and Behaviour) (CNRS).

20 Author contribution. DD and NB designed and performed the study. DD analysed the data. DD

21 wrote the manuscript with the contribution of NB.

22 Data availability statement. All data will be made publicly available. 


\section{Abstract}

24 Predators are thought to prey on individuals that are in poor physical condition, although the evidence

25 supporting this is ambiguous. We tested if sick individuals where more predated using Drosophila

26 melanogaster flies as manipulable preys. We asked whether hunting spiders, trapped from the wild,

27 would selectively prey upon flies with compromised health (i.e. chronically infected or cancerous)

28 versus healthy flies under laboratory conditions. Flies chronically infected with the bacterium

29 Providencia rettgeri, a natural Drosophila pathogen, were not selectively preyed upon by jumping

30 spiders. We strengthened and confirmed our finding with another hunting spider species, small wolf

31 spiders. We discuss that this result supports the hypothesis that chronic infection is associated with

32 reduced symptoms notably to avoid the potentially deadly consequences of host predation on

33 pathogens. We then induced colon cancer in some of the flies and asked whether the presence of

34 cancer led to selective predation; there is little evidence for this, even in vertebrates. As the cancer

35 developed, the incidence of predation by jumping spiders on the afflicted flies increased. We conclude

36 that disease can have different lethal consequences through predation, even in invertebrate species, and

37 that cancer is a factor in selective predation. Our results may explain why early tumours, but not

38 metastasized cancers, are commonly detected in organisms in the wild, as cancer bearing individuals

39 are rapidly eliminated due to the strong selective pressure against them. 


\section{Introduction}

41 In vertebrates, individuals that are injured, or diseased are often preyed upon, as are juveniles who have not reached adult speed or reflex (Furey et al., 2021; Genovart et al., 2010; Mesa, Poe, Gadomski, \& Petersen, 1994; Møller, 2008; Murray, 2002). This is especially true when a predator's preferred type of prey is difficult to catch at the prime of its performance (Temple, 1987), however, there are exceptions (Penteriani et al., 2008). Although this conventional wisdom of selective predation on substandard individuals is largely accepted, only a few studies have tested it empirically. Selective predation can only be said to exist when the relative frequencies of the types of prey in a predator's diet differ from the frequencies of the prey in the environment (Chesson, 1978). Hence, to test the selective prey hypothesis in the wild, data on the types of prey sought by many of the predators and the health status of the whole prey population would be determined. This is obviously difficult to obtain. Furthermore, a prey individual may suffer from different conditions which influence each other and lead to spurious effects. For example, exhaustion from care for large brood increases susceptibility to parasites (Oppliger, Christe, \& Richner, 1996). Thus, the fittest hosts are the ones classified as being sick. Although those information may be vitally important in the context of eco-evolutionary dynamics (Brunner, Anaya-Rojas, Matthews, \& Eizaguirre, 2017; Brunner, Deere, Egas, Eizaguirre, \& Raeymaekers, 2019), the topic has been subjected more to speculation than to empirical study.

Probably the most studied question regarding selective predation is whether predators prey more on individuals with suboptimal conditions over healthy individuals. Even if hosts predators may avoid infected prey to avoid the risk of getting sick themselves (Goren \& Ben-Ami, 2017), it has been suggested, based on field observations, that infections could increase the vulnerability to predation (Adelman, Mayer, \& Hawley, 2017; Duffy, Hall, Tessier, \& Huebner, 2005; Gooding et al., 2020; Miller et al., 2008; Moller \& Erritzoe, 2000; Moller, Erritzoe, \& Tottrup, 2010; Møller \& Nielsen, 2007; Murray, Cary, \& Keith, 2006) and there is some experimental support for this (DeBlieux \& Hoverman, 2019; Gallagher et al., 2019; Johnson, Stanton, Preu, Forshay, \& Carpenter, 2006; Murray, 2002). Consequently, by mediating selective predation, parasites can mediate the relationship between 
predators can reduce vertebrate prey populations (Sih, Crowley, Mcpeek, Petranka, \& Strohmeier, 1985), which seems counterintuitive, as predators are expected to remove preys. However, mathematical models predict that virulent parasites may be selected against if predation disproportionately removes them before they can be transmitted to the host (Packer, Holt, Hudson, Lafferty, \& Dobson, 2003). Without this check on virulent parasites by the predator, more prey may die from lethal infections than from predation. Hence, if selective predation for infected individuals is a common pattern, it may also be a major driver of host and parasite evolution and cannot be ignored any longer (Møller, 2008).

It is also relevant to consider that not all sickness come from infections and that non-infectious diseases could also increase the risk of being predated. In fact, understanding the role of cancer on ecosystem function has been identified as a key endeavour (Dujon, Aktipis, et al., 2021). So far, most of our knowledge is based on the consequence of transmissible cancer on an apex predator (i.e. Tasmanian devil (Cunningham, Johnson, \& Jones, 2020; Hollings, Jones, Mooney, \& Mccallum, 2014; Hollings, Jones, Mooney, \& McCallum, 2016; Woods et al., 2018)), and few to nothing is known about the potential selective predation of prey that are sick due to a non-infectious disease (see (Perret, Gidoin, Ujvari, Thomas, \& Roche, 2020) for a theoretical study). Mutations can occur during the cell replication and division required to grow and maintain multicellular animals, and certain types of mutation, said oncogenic mutations, can lead to the formation of tumours (Aktipis et al., 2015; Albuquerque, Drummond do Val, Doherty, \& de Magalhães, 2018; Hanahan \& Weinberg, 2011; National Cancer Institute, 2020a). In most cases, tumours are benign (Bissell \& Hines, 2011), but they can be malignant, and even fatal (Aktipis et al., 2015; Albuquerque et al., 2018; Hanahan \& Weinberg, 2011; National Cancer Institute, 2020b). Clinical categorization of tumours has been established in unchallenging, even 'optimal' environments (i.e. in the laboratory or clinic), usually to the point of death via organ failure. The impact of tumour progression is likely to influence tremendously individual's life history traits (e.g. lifespan and reproductive output but also competitive and dispersal ability, and pathogen susceptibility), yet, its impact under more natural conditions has largely been neglected (Roche, Møller, DeGregori, \& Thomas, 2017; Marion Vittecoq et al., 2013). Furthermore, 
94 depending on the relationship between tumour development and the health of the prey, predation could

95 affect the selection of oncogenic mutations and thus the risk to develop cancer. To our knowledge, the

96 possible interactions between a predator and a prey that is afflicted with cancer are poorly understood

97 and have not been empirically studied to date (Marion Vittecoq et al., 2013).

98 Here, we induced chronic bacterial infection and colon cancer in prey to understand their role 99 in increasing the likelihood of being predated. We use the fruit fly Drosophila melanogaster, a model 100 which has started recently to be used to study the effect of cancer from an ecological perspective 101 (Arnal et al., 2017; Dawson et al., 2018) and is already a well-characterized model for infectious and 102 non-infectious diseases, as a novel model for sick prey. We assess the predation of flies by hunting 103 spiders, using flies chronically infected by a wild-caught bacterial pathogen (Providencia rettgeri), 104 and have genetically induced cancer, under laboratory-controlled conditions. These conditions allow 105 for the ideal experimental setting to study predation and the role of prey well-being in a population 106 context.

\section{Materials and methods}

\section{Prey and predators.}

109 We used Drosophila melanogaster flies as prey in this study as they are tractable to genetic induction

110 of tumours, are well-defined models for bacterial infection, and allow for control of environmental and

111 genetic differences. Only one sex (males) were used, to avoid sex effects. We induced chronic

112 infection by injecting $23 \mathrm{~nL}$ of a suspension of few thousand cells of the bacterium Providencia 113 rettgeri (strain Dmel, isolated from wild-caught Drosophila melanogaster; Juneja and Lazzaro 2009)

114 in phosphate-buffered saline (PBS) into the abdomen of flies (Canton S line, a wildtype genotype kept 115 in the laboratory since several decades). The same volume of sterile PBS without bacteria was injected 116 into another group of flies that served as the control. Individuals surviving for three days or more after 117 injection of the bacteria have an established chronic infection, as we have previously demonstrated 118 (Duneau et al., 2017). 
119 To induce tumours in the flies, we took advantage of signalling pathways that regulate cell growth in

120 mammals, which have a conserved function in Drosophila, the EGFR and Wnt pathways (Millburn et

121 al., 2016; Mirzoyan et al., 2019; Rudrapatna, Cagan, \& Das, 2012; Villegas, 2019). We used targeted

122 induction of these pathways (Rasv12 for EGFR, APC RNAi for the Wnt pathway) to induce two types

123 of enlargement of the flies digestive tract (i.e. hyperplasia, often called benign tumour, and cancer).

124 Those types of colon cancer is appropriate for this study, as it does not overtly affect physical

125 performance including locomotion, and will thus allow for the study of the interaction of oncogenic

126 phenomena and predation (see Dawson et al. 2018 for locomotion assays in gut cancerous flies in

127 another genetic background). To generate tumours in the gut of Drosophila, flies esg ${ }^{T S}$ (esgGal4,

$128 \mathrm{Gal}^{\mathrm{ts}} 0^{\mathrm{S}}, U A S-G F P$ ) were crossed to either background control flies (Trip stock 35786), flies carrying a

$129 U A S-\operatorname{Ras}^{v 12}$ (Bloomington 64196) or flies carrying a combination of UAS-Ras ${ }^{v / 2}$ (Bloomington

130 641926) and UAS-APC-RNAi (Bloomington Trip stock 28582) combined. The expression of Ras ${ }^{\mathrm{v} 12}$ in

131 progenitor cells stimulates an accelerated turnover and a mild accumulation of epithelial cells in the

132 gut, akin to a dysplastic tissue (Buchon, Broderick, Kuraishi, \& Lemaitre, 2010; Houtz, Bonfini, Bing,

133 \& Buchon, 2019), later also referred as hyperplasia. The overexpression of $\operatorname{Ras}^{v 12}$ combined with the

134 knock-down of $A P C$ leads to increased proliferation, and accumulation of progenitor cells and

135 epithelial cells in the gut, reminiscent of an intestinal disseminated tumour (Wang et al., 2013), later

136 also referred as cancerous. F1 flies from these crosses were raised at $18^{\circ} \mathrm{C}$ (Gal4 off, transgene

137 expression off, normal development and emergence), and 3 days after emergence were switched to

$13829^{\circ} \mathrm{C}$ (Gal4 on, transgene expression on) for 10 or 20 days before performing the experiment. As in

139 (Wang et al., 2013), crosses with WT flies showed mild tissue renewal (restricted GFP signal), flies

140 with expressing $\operatorname{Ras}^{v 12}$ showed disseminated GFP in their gut and flies expressing $\operatorname{Ras}^{v 12}$ and APC

141 RNAi showed gut enlargement and GFP accumulation. The longest the induction is done and the

142 strong is the phenotypes leading to a gradient from induced hyperplasia for 10 days (i.e. mild colon

143 enlargement) to induced cancer for 20 days (i.e. limit to the complete obstruction of the colon).

144 We used two families of hunting spiders as predators: jumping spiders of several species from

145 the family of Salticidae (see illustration in Fig. 1) and small wolf spiders from the family of Lycosidae 
146 (likely Pardosa lugubris). Both jumping and wolf spiders hunt by wandering rather than by using

147 webs as traps.

148 Jumping spiders have the sharpest vision of any arthropod, even surpassing many vertebrates

149 (Land \& Nilsson, 2012). They hunt during the day and rely on this astonishing vision when catching a

150 prey. Similar to the way a cat stalks its prey, jumping spiders turn towards their prey, directed by a

151 pair of lateral eyes that provide a nearly panoramic field of view with the ability to discern motion

152 (Zurek \& Nelson, 2012). Then, the spiders track, approach, and jump on the prey. The vision accuracy

153 is conferred by two pairs of forward-facing eyes that also provide a precise perception of depth

154 (Nagata et al., 2012; Zurek, Taylor, Evans, \& Nelson, 2010).

After having tested jumping spiders as predator, we decided to test whether infected individuals would still not be more likely to be eaten by another type of hunting spider species with different hunting behaviour, wolf spiders. This was additionally performed to strengthen our "negative" result. Wolf and jumping spiders have already successfully been used to test for selective predation (Holmberg \& Turnbull, 1982; Vickers \& Taylor, 2018). Wolf spiders are generally nocturnal hunters and their eyes function mainly as low-light movement detectors, however Pardosa species are mostly hunting during the day (Edgar, 1969). Their vision is not as acute as that of jumping spiders (Land \& Nilsson, 2012). The use of visual cues in prey detection and orientation have only been wellstudied in jumping spiders, and empirical evidence suggests that wolf spiders rely more on vibrations to capture their prey than on vision (Lizotte \& Rovner, 1988). Hence, the differences between these two types of hunting spiders primarily lie in their ability to prey on flies that are at rest. In an environment where there is no place to hide, jumping spiders would likely prey equally well on moving and non-moving prey, and selective predation in this case should depend largely on the prey's capacity to escape.

\section{Predation trials}

170 Predation trials were performed during the day by incubating five healthy and five sick flies, agematched, at $20^{\circ} \mathrm{C}$ with a spider in a round plastic box $(11.5 \mathrm{~cm} \times 8.5 \mathrm{~cm}$, see illustration in fig. 1B) 
172 containing a wet piece of cotton or foam. The flies were first added to the box to settle before the

173 introduction of the predators. After about $30 \mathrm{~min}$, spiders were put in the box. The trials generally

174 lasted for about 4 hours or were stopped when $50 \%$ of the flies had been preyed upon, as, when

175 scoring only at the end of the experiment, it allows to score the most extreme result (i.e. all individuals

176 from one treatment have been eaten before the other treatment). Even if no spiders were starved before

177 the experiment, this goal was sometimes exceeded as some spiders ate faster than expected. Individual

178 spiders have never been used twice as predators within an experiment.

To determine the number of surviving flies that were infected, we ground the remaining flies at the end of the predation period and suspended the mixture in $250 \mu \mathrm{L}$ of Luria-Bertani (LB) medium.

A droplet of five microliters of the resulting suspension was spread on a petri dish filled with agar containing LB medium, and the plates were incubated overnight at $37^{\circ} \mathrm{C}$ to assess for the presence of P. rettgeri. We calculated the proportion of infected flies at the end of predation period by determining the number of droplets in which $P$. rettgeri were present. For a control comparison, we performed the same process with infected and healthy flies, but did not expose them to predatory spiders. Our protocol consistently led to the induction of tumour, even if interindividual variation in tumour size exist which can be a source of variation in our trials. In the unlikely event that some individuals were considered has carrying a tumour but did not, those individuals would reduce the strength of our signal as they would be like control individuals. The number of surviving flies that had cancer were counted by dissecting all surviving flies and observing their guts under a fluorescent microscope, which reveals the presence/absence of cancer.

\section{Statistical analysis}

Statistical analysis were performed using R, version 4.1 (R Core Team, 2020). The use of the Fisher exact test or a chi-squared test would have permitted us to test for every trial regardless of whether the number of flies from a particular category was more or less preyed upon than those from another category. However, we used a hypergeometric distribution instead of a Chi-squared distribution because, as flies were preyed upon, the population size decreased and we only had information on predation rate per treatment at the end of the experiment. The $p$-value for each experimental trial was 
added up and compared to the summed $p$-value obtained by simulating random trials. We assessed the

200 overall $p$-value by determining the number of simulated trials required to have an observed result

201 (summed $p$-value observed) as probable as the simulation (summed $p$-value simulated). Hence, a $p$ -

202 value of 0.05 indicated that 20 trials would be sufficient to have the same result as the empirical data

203 by chance, whereas a $p$-value of 0.0001 meant that 10,000 trials would be required to achieve the same

204 result as the empirical data by chance. We used the Manly Alpha Index as the preference index to

205 illustrate the selective predation on sick individuals (index 0: preference for healthy individuals, index

206 0.5: no preference, index 1: preference for sick individuals). It was calculated as log (total flies sick /

207 flies sick but not eaten) / [(log(total flies sick / flies sick but not eaten $)+\log ($ total flies healthy / flies

208 healthy but not eaten)] as established by Manly (1972). To test whether the preference index for sick

209 individuals increased with the severity of the cancer, we considered hyperplasia after 10 and 20 days

210 of induction and cancer after 10 days and 20 days as ordinal variables. This was used because although

211 we knew the rank of severity (i.e. from inducing hyperplasia for 10 days to inducing cancer for 20

212 days), we could not know the size of the differences among them. This allowed us to test in a single

213 model (i.e. using an ordinal logistic regression) for the increase of the preference index with the

214 increase in cancer severity.

\section{Ethical note}

216 All spiders in the study were obtained from the wild during their daily activity and kept for less than a

217 week, eventually fed with healthy Drosophila. Spiders used for testing the effect of cancer were

218 sampled and tested on the Cornell University campus (Ithaca, NY, USA) and those used for testing the

219 effect of infectious diseases were sampled and tested on the campus of the University of Toulouse 3

220 (Toulouse, France). All individuals have been released in the wild at the area they have been caught

221 shortly after the experiments were performed. 


\section{Results}

223 Predation of chronically infected flies by hunting spiders. We tested whether chronic infection of 224 the male flies by $P$. rettgeri affected the risk of being preyed upon by the spiders. The flies had been 225 infected for several days before exposure to the spiders, and their immune response was expected to be 226 activated (Chambers, Jacobson, Khalil, \& Lazzaro, 2019). Despite using two predator species, we did 227 not detect selective predation by either of the hunting spider types (Fig. 2A and B for jumping and wolf spiders, respectively).

Predation of flies with cancer by hunting spiders. We asked if cancer of the gut, which we induced,

230 affected the risk for predation of male flies by the hunting spiders. Hyperplasia is the enlargement of 231 an organ or tissue caused by increased cell division and is often an initial stage in the development of 232 cancer. We observed that flies in this early hyperplastic stage $\left(e s g^{t s}>U A S-\operatorname{Ras}^{v 12}\right)$ did not show an 233 increased likelihood of getting preyed upon by the jumping spiders, which are active diurnal hunters (Fig. 3A). However, jumping spiders did catch more successfully flies with an advanced stage of cancer $\left(e s g^{t s}>U A S-R a s^{v 12}, U A S-A P C-I R\right)$ compared with healthy flies. Furthermore, the preference index for sick individuals increased with the length of time after the tumour had been induced (Fig. 3B).

\section{Discussion}

Many diseases do not kill their hosts and are considered benign in optimal conditions, such as in a clinic or laboratory. However, it is very likely that non-lethal illnesses still increase the risk of mortality through indirect interactions with other environmental factors. Indeed, being sick may reduce foraging and mating abilities, increase the risk for lethal superinfections, or of being preyed upon. Even though many biological questions are presently being addressed using an integrative approach, the question of whether a non-lethal disease is truly benign in natural conditions seems to have been overlooked in many cases. We hope to generate interest in evaluating the lethality of diseases when their interaction with other risks, such as predation, is considered. Chronic infection by 
247 a wild-caught Drosophila pathogen did not significantly affect the risk of being preyed upon in the

248 laboratory. In contrast, we observed that while the presence of early stage tumours did not change

249 predation risk, the presence of advanced cancer did compared to age-matched controls.

Little is known about selective predation in individuals with non-infectious diseases. The prevailing opinion that general health, which can be affected by non-infectious sickness, correlates with the risk of being preyed upon, is largely observational (Genovart et al., 2010; Hoey \& McCormick, 2004). Nonetheless, although we should not be jumping to hasty conclusions, our results on the effects of non-infectious disease on selective predation suggests a stronger selective pressure than natural chronic infections.

Cancers are common in multicellular organisms and can occur whenever cells evade the normal cell checkpoints that control cell division, proliferation, and apoptosis, thus leading to uncontrolled cell division (Aktipis et al., 2015). Individuals always have some tumours, most of which never become lethal (Abu-Helil \& van der Weyden, 2019; Bissell \& Hines, 2011). Our understanding of oncogenic phenomena in wild populations of animals is limited, in particular whether tumours that are clinically non-lethal affect the well-being of organisms in the wild (McAloose \& Newton, 2009; Pesavento, Agnew, Keel, \& Woolard, 2018; M. Vittecoq et al., 2015; Marion Vittecoq et al., 2013). Theoretical modelling further suggests that biotic interactions complicate the predictions regarding the impact of cancer on populations and that prey and predator populations are likely to suffer differently (Perret et al., 2020). If tumour formation is inevitable, it is likely that multicellular organisms have evolved ways to control and tolerate them, perhaps resulting in a trade-off between surviving the tumour and surviving other perils, such as infections or predation (Pavard \& Metcalf, 2019). In some cases, selection for tumour tolerance may have arisen from selection for tolerance to other factors, 269 perhaps explaining why early stages of cancer, such as the colon hyperplasia that we induced in 270 Drosophila, do not change the likelihood of being preyed upon. In our study, when the tumour 271 developed into a cancer, predation of the flies increased, suggesting that uncontrolled tumours strongly increase the likelihood of being preyed upon. This conclusion supports the idea that individuals with uncontrolled tumours will suffer the risk of increased predation compared with healthy individuals. 

populations (Marion Vittecoq et al., 2013).

We do not know why cancerous flies are more predated than their age-matched controls or even if this result could be to some extend dependent on the sex of the fly. Jumping spiders have been shown to be able to choose prey based on odour and coloration (Vickers \& Taylor, 2018). It would be difficult to interpret why such behaviour would have evolved in the context of cancer but we cannot exclude that, spiders recognized and preferred eating cancerous flies. Assays in gut cancerous flies from another study in another genetic background suggests that induction of colon cancer does not affect strongly fly locomotion (Dawson et al., 2018). However, there is still the possibility that cancerous flies have worst reflex than healthy flies or that subtle locomotion differences may be enough to explain a difference in the chance to escape predation. Our results lay the premise of future studies on understanding the mechanisms explaining the reasons for this difference. cancer cells have already been considered as a parasitic species consuming the host's resources after having emerged from healthy cells (Capp \& Thomas, 2020; Duesberg, Mandrioli, McCormack, \& Nicholson, 2011). However, if both reduce viability and survival, infectious diseases are, unlike oncogenic processes, under selective pressure to ensure transmission of the pathogen to another host. For both non-infectious diseases and cancer, selective predation could increase the selection against the sickness, as diseases that are moderate and non-lethal could lead to a higher risk of the host being 296 preyed upon, resulting in mortality rates that are similar to those of infectious diseases. With infectious 297 diseases, there may be additional consequences. First, selective predation could affect the transmission 298 of pathogens, spreading them through predator feces over long distances. Second, it might affect 299 epidemics, either preventing them by removing parasite spreaders from the host population (Duffy et 
301 them in dead hosts (Strauss et al., 2016). An additional consideration is that predation may affect the

302 evolution of parasite virulence. It is generally assumed that predation can reduce virulence because

303 hosts with rapidly proliferating parasites would suffer more from the infection and may be eaten

304 before transmitting the parasite to another host, whereas the less rapidly proliferating parasite would

305 impact less host health and would be transmitted before the host is eaten (Moller et al., 2010).

306 However, lower virulence could evolve also through lower pathogenicity, that is by inducing less

307 damage to the host, and not only through reduced proliferation. The most important factor being that

308 bacteria can proliferate within their host as long as the symptoms do not increase the risk of predation.

309 The bacteria studied here, P. rettgeri, was obtained from the wild and is prevalent in populations of $D$.

310 melanogaster (Juneja \& Lazzaro, 2009). Despite being chronic and the fact that the pathogen can

311 trigger an immune response through the course of the infection (Chambers et al., 2019; Duneau et al.,

312 2017), the chronic infection did not increase the predation by the two species of predator we used in

313 our study. This result supports the hypothesis that chronic infections are selected for such that the

314 symptoms that enhance predation are reduced.

315 It is reasonable to assume that the success of predators is not simply due to favourable luck. In

316 fact, selective predation may be more the rule than the exception and is likely to have a role on the

317 evolution of diseases, infectious or not (Møller, 2008). On the one hand, selective predation on sick

318 individuals is likely to counter-select against parasites or genetic diseases more strongly than if

319 selection occurred upon disease-mediated host death later in life in absence of predation. On the other

320 hand, in the same way that some parasites evolved to manipulate their host to increase transmission to

321 intermediate hosts (Hughes \& Libersat, 2019), parasites may have evolved to make their hosts less

322 conspicuous to predation, for example, by interfering with the search for mates or by lessening the

323 effects of the disease on the host; for example, by reducing symptoms. Because cancer progression

324 generally results in the death of the organism, we cannot expect the incidence of lethal cancer to have

325 evolved in the same way as parasites, except for transmissible cancers such as in Tasmanian devils

326 (Dujon, Bramwell, Roche, Thomas, \& Ujvari, 2021). We argue that selective predation on prey with 
327 cancer may be one of the reasons why tumours are commonly tolerated in animals, where advanced

328 cancer is only rarely detected.

\section{$329 \quad$ References}

330 Abu-Helil, B., \& van der Weyden, L. (2019). Metastasis in the wild: investigating metastasis in non-

331 laboratory animals. Clinical and Experimental Metastasis, 36(1), 15-28. doi:10.1007/s10585019-09956-3

Adelman, J. S., Mayer, C., \& Hawley, D. M. (2017). Infection reduces anti-predator behaviors in house finches. Journal of Avian Biology, 48(4), 519-528. doi:10.1111/jav.01058

Aktipis, C. A., Boddy, A. M., Jansen, G., Hibner, U., Hochberg, M. E., Maley, C. C., \& Wilkinson, G.

Brunner, F. S., Anaya-Rojas, J. M., Matthews, B., \& Eizaguirre, C. (2017). Experimental evidence that

Albuquerque, T. A. F., Drummond do Val, L., Doherty, A., \& de Magalhães, J. P. (2018). From humans to hydra: patterns of cancer across the tree of life. Biological Reviews, 93(3), 1715-1734. doi:10.1111/brv.12415

Arnal, A., Jacqueline, C., Ujvari, B., Leger, L., Moreno, C., Faugere, D., ... Thomas, F. (2017). Cancer brings forward oviposition in the fly Drosophila melanogaster. Ecology and Evolution, 7(1), 272-276. doi:10.1002/ece3.2571

Bissell, M. J., \& Hines, W. C. (2011). Why don't we get more cancer? A proposed role of the microenvironment in restraining cancer progression. Nature Medicine, 17(3), 320-329. doi:10.1038/nm.2328 parasites drive eco-evolutionary feedbacks. Proceedings of the National Academy of Sciences, 114(14), 3678-3683. doi:10.1073/pnas.1619147114 
Brunner, F. S., Deere, J. A., Egas, M., Eizaguirre, C., \& Raeymaekers, J. A. M. (2019). The diversity of eco $\square$ evolutionary dynamics: Comparing the feedbacks between ecology and evolution across scales. Functional Ecology, 33(1), 7-12. doi:10.1111/1365-2435.13268

Buchon, N., Broderick, N. A., Kuraishi, T., \& Lemaitre, B. (2010). Drosophila EGFR pathway coordinates stem cell proliferation and gut remodeling following infection. BMC Biology, 8. doi:10.1186/1741-7007-8-152

Capp, J. P., \& Thomas, F. (2020). A Similar Speciation Process Relying on Cellular Stochasticity in Microbial and Cancer Cell Populations. IScience, 23(9), 1-12. doi:10.1016/j.isci.2020.101531

Chambers, M. C., Jacobson, E., Khalil, S., \& Lazzaro, B. P. (2019). Consequences of chronic bacterial infection in Drosophila melanogaster. PloS One, 14(10), e0224440. doi:10.1371/journal.pone.0224440

Chesson, J. (1978). Measuring preference in selective predation. Ecology, 59(2), 211-215. doi:10.2307/1936364

Cunningham, C. X., Johnson, C. N., \& Jones, M. E. (2020). A native apex predator limits an invasive mesopredator and protects native prey: Tasmanian devils protecting bandicoots from cats. Ecology Letters, 23(4), 711-721. doi:10.1111/ele.13473

Dawson, E. H., Bailly, T. P. M., Dos Santos, J., Moreno, C., Devilliers, M., Maroni, B., ... Mery, F. (2018). Social environment mediates cancer progression in Drosophila. Nature Communications, 9(1), 3574. doi:10.1038/s41467-018-05737-w

DeBlieux, T., \& Hoverman, J. (2019). Parasite-induced vulnerability to predation in larval anurans. Diseases of Aquatic Organisms, 135(3), 241-250. doi:10.3354/dao03396

Duesberg, P., Mandrioli, D., McCormack, A., \& Nicholson, J. M. (2011). Is carcinogenesis a form of speciation? Cell Cycle, 10(13), 2100-2114. doi:10.4161/cc.10.13.16352

Duffy, M. A., Hall, S. R., Tessier, A. J., \& Huebner, M. (2005). Selective predators and their parasitized prey: Are epidemics in zooplankton under top-down control? Limnology and 
Dujon, A. M., Aktipis, A., Alix-Panabières, C., Amend, S. R., Boddy, A. M., Brown, J. S., ... Ujvari, Applications, 14(4), 877-892. doi:10.1111/eva.13190

Dujon, A. M., Bramwell, G., Roche, B., Thomas, F., \& Ujvari, B. (2021). Transmissible cancers in mammals and bivalves: How many examples are there?: Predictions indicate widespread occurrence. BioEssays, 43(3), 1-10. doi:10.1002/bies.202000222

Duneau, D., Ferdy, J.-B., Revah, J., Kondolf, H. C., Ortiz, G. A., Lazzaro, B. P., \& Buchon, N. (2017). Stochastic variation in the initial phase of bacterial infection predicts the probability of survival

Edgar, W. D. (1969). Prey and predators of the Wolf spider Lycosa lugubris. Journal of Zoology, in Drosophila melanogaster. ELife, 6, e28298. doi:10.7554/eLife.28298

Furey, N. B., Bass, A. L., Miller, K. M., Li, S., Lotto, A. G., Healy, S. J., ... Hinch, S. G. (2021). Infected juvenile salmon can experience increased predation during freshwater migration. Royal

Gallagher, S. J., Tornabene, B. J., DeBlieux, T. S., Pochini, K. M., Chislock, M. F., Compton, Z. A.,

Genovart, M., Negre, N., Tavecchia, G., Bistuer, A., Parpal, L., \& Oro, D. (2010). The young, the

Gooding, E. L., Kendrick, M. R., Brunson, J. F., Kingsley-Smith, P. R., Fowler, A. E., Frischer, M. E., \& Byers, J. E. (2020). Black gill increases the susceptibility of white shrimp, Penaeus setiferus 
Goren, L., \& Ben-Ami, F. (2017). To eat or not to eat infected food: a bug's dilemma. Hydrobiologia, 798(1), 25-32. doi:10.1007/s10750-015-2373-3

Hall, S. R., Cáceres, C. E., Duffy, M. A., \& Cáceres, C. E. (2005). Selective predation and productivity jointly drive complex behavior in host-parasite systems. American Naturalist, 165(1), 70-81. doi:10.1086/426601

Hanahan, D., \& Weinberg, R. A. (2011). Hallmarks of cancer: The next generation. Cell, 144(5), 646674. doi:10.1016/j.cell.2011.02.013

Hoey, A. S., \& McCormick, M. I. (2004). Selective predation for low body condition at the larvaljuvenile transition of a coral reef fish. Oecologia, 139(1), 23-29. doi:10.1007/s00442-004-14893

Hollings, T., Jones, M., Mooney, N., \& Mccallum, H. (2014). Trophic Cascades Following the

Hollings, T., Jones, M., Mooney, N., \& McCallum, H. (2016). Disease-induced decline of an apex predator drives invasive dominated states and threatens biodiversity. Ecology, 97(2), 394-405. doi:10.1890/15-0204.1

Holmberg, R. G., \& Turnbull, A. L. (1982). Selective predation in a euryphagous invertebrate predator, pardosa vancouveri (Arachnida: Araneae). The Canadian Entomologist, 114(3), 243257. doi:10.4039/Ent114243-3

Houtz, P., Bonfini, A., Bing, X., \& Buchon, N. (2019). Recruitment of adult precursor cells underlies limited repair of the infected larval midgut in Drosophila. Cell Host and Microbe, 26(3), 412425.e5. doi:10.1016/j.chom.2019.08.006 R45-R47. doi:10.1016/j.cub.2018.12.001 
Johnson, P. T. J., Stanton, D. E., Preu, E. R., Forshay, K. J., \& Carpenter, S. R. (2006). Dining on disease: How interactions between infection and environment affect predation risk. Ecology, 87(8), 1973-1980. doi:10.1890/0012-9658(2006)87[1973:DODHIB]2.0.CO;2

Juneja, P., \& Lazzaro, B. P. (2009). Providencia sneebia sp. nov. and Providencia burhodogranariea sp. nov., isolated from wild Drosophila melanogaster. International Journal of Systematic and Evolutionary Microbiology, 59(5), 1108-1111. doi:10.1099/ijs.0.000117-0

Land, M. F., \& Nilsson, D.-E. (2012). Animal eyes. (Oxford University Press, Ed.) (Oxford Ani). Oxford. Retrieved from http://sro.sussex.ac.uk/id/eprint/38226

Lizotte, R. S., \& Rovner, J. S. (1988). Nocturnal capture of fireflies by lycosid spiders: visual versus vibratory stimuli. Animal Behaviour, 36(6), 1809-1815. doi:10.1016/S0003-3472(88)80120-9

Manly, B. F. J. (1972). Tables for the analysis of selective predation experiments. Researches on Population Ecology, 14(1), 74-81. doi:10.1007/BF02511186

McAloose, D., \& Newton, A. L. (2009). Wildlife cancer: A conservation perspective. Nature Reviews Cancer, 9(7), 517-526. doi:10.1038/nrc2665

Mesa, M. G., Poe, T. P., Gadomski, D. M., \& Petersen, J. H. (1994). Are all prey created equal? A review and synthesis of differential predation on prey in substandard condition. Journal of Fish Biology, 45, 81-96. doi:10.1111/j.1095-8649.1994.tb01085.x

Millburn, G. H., Crosby, M. A., Gramates, L. S., Tweedie, S., Gelbart, W., Perrimon, N., ... Baker, P. (2016). Fly Base portals to human disease research using Drosophila models. DMM Disease Models and Mechanisms, 9(3), 245-252. doi:10.1242/dmm.023317

Miller, M. W., Swanson, H. M., Wolfe, L. L., Quartarone, F. G., Huwer, S. L., Southwick, C. H., \& Lukacs, P. M. (2008). Lions and prions and deer demise. PLoS ONE, 3(12). doi:10.1371/journal.pone.0004019

Mirzoyan, Z., Sollazzo, M., Allocca, M., Valenza, A. M., Grifoni, D., \& Bellosta, P. (2019). Drosophila melanogaster: A model organism to study cancer. Frontiers in Genetics, 10, 1-16. 
Møller, A. P. (2008). Interactions between interactions: Predator-prey, parasite-host, and mutualistic interactions. Annals of the New York Academy of Sciences, 1133, 180-186. doi:10.1196/annals.1438.007

Moller, A. P., \& Erritzoe, J. (2000). Predation against birds with low immunocompetence. Oecologia, 122(4), 500-504. doi:10.1007/s004420050972

Moller, A. P., Erritzoe, J., \& Tottrup, N. J. (2010). Predators and microorganisms of prey: goshawks prefer prey with small uropygial glands. Functional Ecology, 24(3), 608-613.

Møller, A. P., \& Nielsen, J. T. (2007). Malaria and risk of predation: A comparative study of birds. doi:10.1111/j.1365-2435.2009.01671.x

Murray, D. L. (2002). Differential body condition and vulnerability to predation in snowshoe hares. Journal of Animal Ecology, 71(4), 614-625. doi:10.1046/j.1365-2656.2002.00632.x

Murray, D. L., Cary, J. R., \& Keith, L. B. (2006). Interactive effects of sublethal nematodes and nutritional status on snowshoe hare vulnerability to predation. The Journal of Animal Ecology,

Nagata, T., Koyanagi, M., Tsukamoto, H., Saeki, S., Isono, K., Shichida, Y., ... Terakita, A. (2012). Depth perception from image defocus in a jumping spider. Science, 335(6067), 469-471.

National Cancer Institute. (2020a). NCI Dictionary of Cancer Terms. Retrieved from doi:10.1126/science. 1211667 
Packer, C., Holt, R. D., Hudson, P. J., Lafferty, K. D., \& Dobson, A. P. (2003). Keeping the herds healthy and alert: Implications of predator control for infectious disease. Ecology Letters, 6(9), 797-802. doi:10.1046/j.1461-0248.2003.00500.x

Pavard, S., \& Metcalf, C. (2019). Trade-offs between mortality components in life history evolution: the case of cancers. Human Evolutionary Demography, 1-26.

Penteriani, V., Del Mar Delgado, M., Bartolommei, P., Maggio, C., Alonso-Alvarez, C., \& Holloway, G. J. (2008). Owls and rabbits: Predation against substandard individuals of an easy prey. Journal of Avian Biology, 39(2), 215-221. doi:10.1111/j.0908-8857.2008.04280.x

Perret, C., Gidoin, C., Ujvari, B., Thomas, F., \& Roche, B. (2020). Predation shapes the impact of cancer on population dynamics and the evolution of cancer resistance. Evolutionary Applications, 13(7), 1733-1744. doi:10.1111/eva.12951

Pesavento, P. A., Agnew, D., Keel, M. K., \& Woolard, K. D. (2018). Cancer in wildlife: patterns of emergence. Nature Reviews Cancer, 18(10), 646-661. doi:10.1038/s41568-018-0045-0

R Core Team. (2020). R: A language and environment for statistical computing. Vienna, Austria. Retrieved from https://www.r-project.org/

Roche, B., Møller, A. P., DeGregori, J., \& Thomas, F. (2017). Cancer in Animals: Reciprocal Feedbacks Between Evolution of Cancer Resistance and Ecosystem Functioning. In Ecology and Evolution of Cancer (pp. 181-191). Elsevier. doi:10.1016/B978-0-12-804310-3.00013-2

Rudrapatna, V. A., Cagan, R. L., \& Das, T. K. (2012). Drosophila cancer models. Developmental Dynamics, 241(1), 107-118. doi:10.1002/dvdy.22771

Sih, A., Crowley, P., Mcpeek, M., Petranka, J., \& Strohmeier, K. (1985). Predation, Competition, and Prey Communities: A Review of Field Experiments. Annual Review of Ecology and Systematics, 16(1), 269-311. doi:10.1146/annurev.es.16.110185.001413

Strauss, A. T., Shocket, M. S., Civitello, D. J., Hite, J. L., Penczykowski, R. M., Duffy, M. A., ... Hall, S. R. (2016). Habitat, predators, and hosts regulate disease in Daphnia through direct and 
Temple, S. A. (1987). Do predators always capture substandard individuals disproportionately from prey populations. Ecology, 68(3), 669-674. doi:10.2307/1938472

Vickers, M. E., \& Taylor, L. A. (2018). Odor alters color preference in a foraging jumping spider. Behavioral Ecology, 29(4), 833-839. doi:10.1093/beheco/ary068

Villegas, S. N. (2019). One hundred years of Drosophila cancer research: No longer in solitude. DMM Disease Models and Mechanisms, 12(4). doi:10.1242/dmm.039032

Vittecoq, M., Ducasse, H., Arnal, A., Møller, A. P., Ujvari, B., Jacqueline, C. B., ... Thomas, F. (2015). Animal behaviour and cancer. Animal Behaviour, 101, 19-26. doi:10.1016/j.anbehav.2014.12.001

Vittecoq, Marion, Roche, B., Daoust, S. P., Ducasse, H., Missé, D., Abadie, J., ... Thomas, F. (2013). Cancer: A missing link in ecosystem functioning? Trends in Ecology and Evolution.

Wade, M. J., \& Kalisz, S. (1990). The causes of natural selection. Evolution, 44(8), 1947-1955. doi:10.1111/j.1558-5646.1990.tb04301.x

Wang, C., Zhao, R., Huang, P., Yang, F., Quan, Z., Xu, N., \& Xi, R. (2013). APC loss-induced spiders. Vision Research, 66, 26-30. doi:10.1016/j.visres.2012.06.011 the vision-based behaviour of jumping spiders. Journal of Experimental Biology, 213(14), 2372- 
bioRxiv preprint doi: https://doi.org/10.1101/2020.07.01.182824; this version posted September 28, 2021. The copyright holder for this preprint (which was not certified by peer review) is the author/funder, who has granted bioRxiv a license to display the preprint in perpetuity. It is made available under aCC-BY-NC-ND 4.0 International license. 


\section{Figure legends}

529 Figure 1. Photograph of a jumping spider consuming Drosophila melanogaster flies in the laboratory.

530 Figure 2. Predation by hunting spiders on a population of Drosophila melanogaster Canton S, of

531 either healthy flies or flies chronically infected with P. rettgeri. A. Predation by jumping spiders

532 (Hypergeometric test: $\mathrm{n}=27$ trials, $p$-value $>0.05$, Median pref. index $=0.64$ ) B. Predation by wolf

533 spiders (Hypergeometric test: $\mathrm{n}=30$ trials, $p$-value $>0.05$, Median pref. index $=0.43$ ). Each dot

534 represents the proportion of individuals eaten over five flies and the lines connect the groups of

535 individuals from a same trial. Each trial represents ten flies (five from each type) presented to one

536 spider at once. Preference index is calculated as in Manly (1972) and ranges from 0 to 1, from a

537 preference to healthy flies to a preference for sick flies, respectively.

538 Figure 3. Predation by jumping spiders in a population of Drosophila melanogaster that were either

539 healthy or in which colon tumours (hyperplasia) had been induced. Tumour size increased with

540 induction time, during which uncontrolled cell division occurred. A. Uncontrolled cell division was

541 triggered for 10 or 20 days in $\operatorname{esg}^{T S}>\operatorname{Ras}^{v 12}$ flies to lead to hyperplasia (respectively with $\mathrm{n}=17$ and

54215 trials). In both cases, individuals with hyperplasia were not differently predated upon compared

543 with the healthy individuals. B. Fast uncontrolled cell division was triggered for 10 or 20 days in $\operatorname{esg}^{T S}$

$544>\operatorname{Ras}^{v 12}, A P C-R N A i$ flies to lead to cancer (respectively with $\mathrm{n}=16$ and 20 trials). In both cases,

545 individuals with cancer were more likely to be predated upon than individuals which did not have

546 cancer. This pattern tended to be stronger as the tumour grew larger (Ordinal logistic regression:

$547 \mathrm{LRT}=8.07, \mathrm{df}=1, \mathrm{p}=0.004)$. Each dot in A and B represents the proportion of individuals eaten over

548 five flies and the lines connect the groups of individuals from a same trial. Each trial represents ten

549 flies (five from each type) presented to one spider at once. Preference index is calculated as in Manly

550 (1972) and ranges from 0 to 1 , from a preference to healthy flies to a preference for sick flies,

551 respectively. 


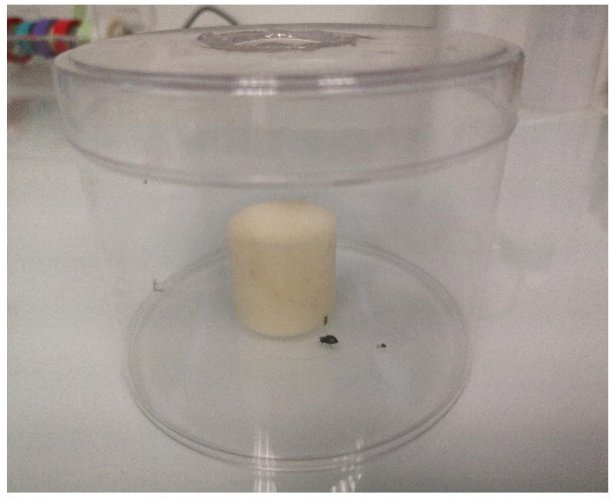



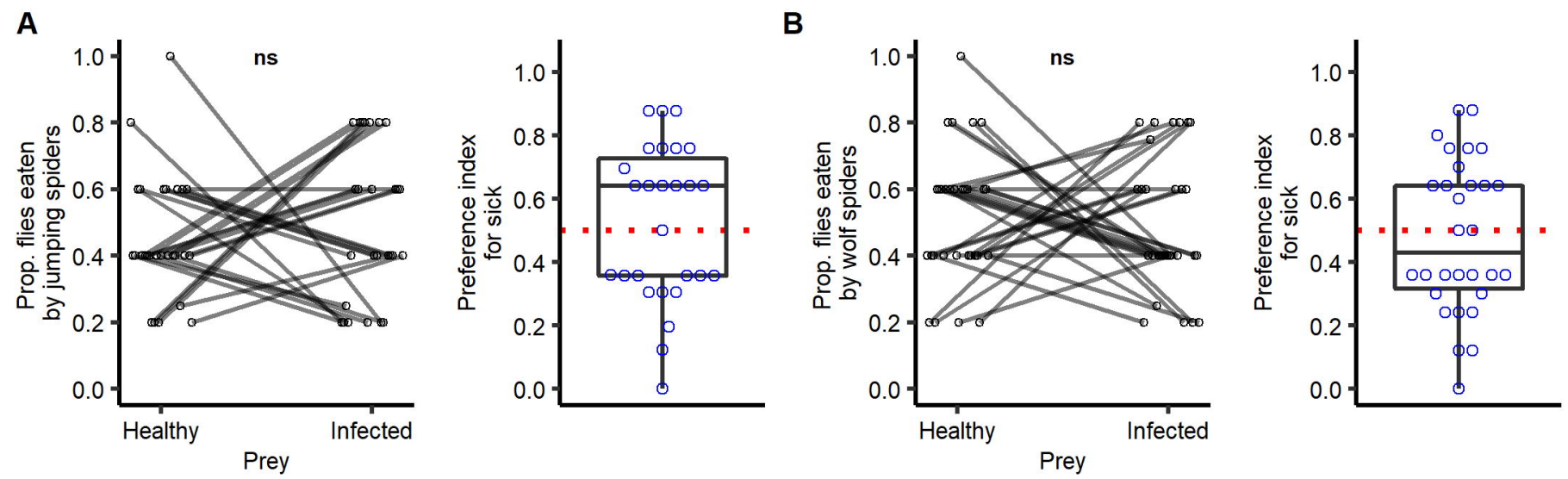

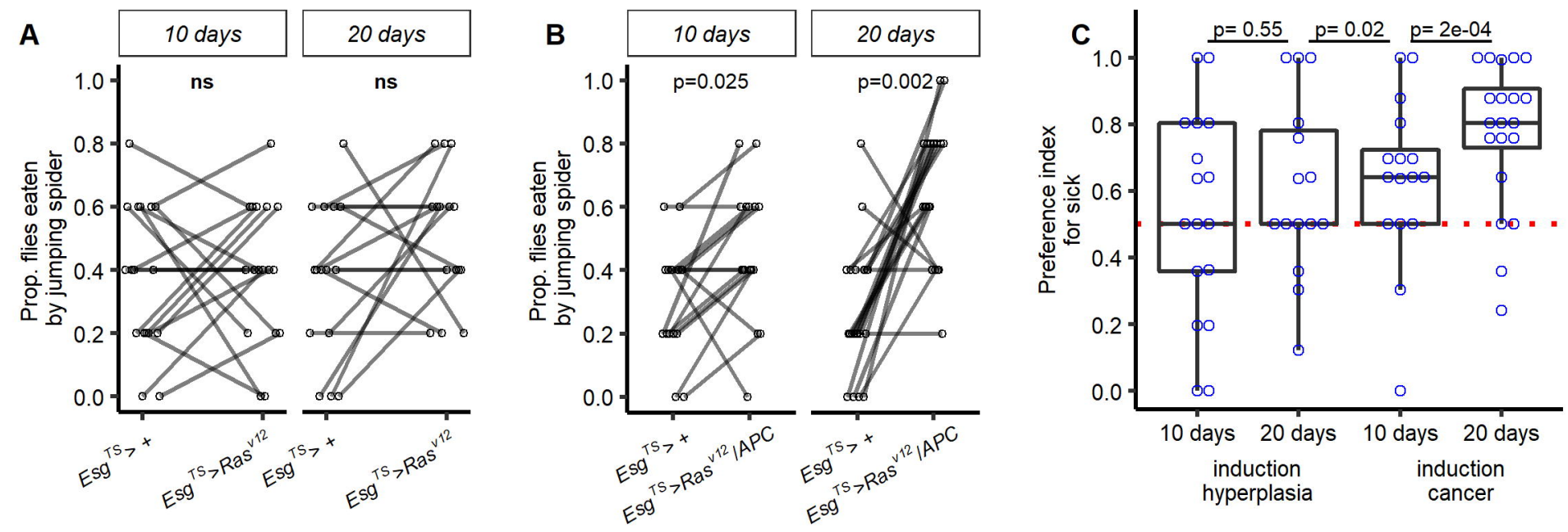